\title{
Е.О. Предвечнова
}

\section{СЕМАНТИКА ОБРАЗА-СИМВОЛА ВРЕМЕНИ В «ТРАГИЧЕСКОЙ COHATE» OP 39 C-MOLL H.K. METHEPA}

\begin{abstract}
В статье осмысливается трагедийное мироощущение художника в эпоху Серебряного века, рассматриваются проблемь экзистенциального понимания природы искусства и содержания музыкального текста на примере «Трагической сонатыл» ор. 39 c-moll Н.К. Метнера. Выявлена драматургическая концепция сонаты, связанная с особенностями философского мировосприятия времени, в аспекте экстрамузыкальной и интрамузыкальной семантики. Рассмотрены особенности музыкального мылиления композитора и «структурно-семантического инварианта жанра» сонаты. Впервые представлен логикосемантический анализ «Трагической сонаты» и образующий с ней цикл «Утренней песни» в диалоге образов-символов Времени и Вечности.

Ключевые слова: Н.К. Метнер, фортепианное творчество, «Трагическая соната», «Утренняя песнь», семантический анализ, семантика образов-символов Времени.
\end{abstract}

Художественная картина мира Серебряного века формировалась под воздействием событий рубежа XIX-XX вв. - эпохи перелома, кризиса, пронизанной особым духом противоречия и эсхатологизма. Трагическое мироощущение конца старого века и тревожное ожидание будущего свойственно художникам переходного исторического периода, пережившим разрушительные мировые войны и революции, потрясшие Россию. Л.Н. Толстой так описывает это сложное время: «Век и конец века на евангельском языке не означает конца и начала столетия, но означает конец одного мировоззрения, одной веры, одного способа общения людей и начало другого мировоззрения, другой веры, другого способа общения» [1. С. 231]. Возникла необходимость осмыслить происходящее и представить новую художественную картину мира, создать новые символические образы и вместе с тем сохранить систему духовно-нравственных ценностей, определяющих основы русской и мировой культуры в целом.

Образ прошлого, сохранение традиций уходящего времени, «трагический дух» современной эпохи значимы в творчестве русского композитора, пианиста, педагога и публициста Н.К. Метнера, как и в творчестве ряда его современников. Новое мироощущение пространственно-временного континуума, противостояние «Божественного порядка» духу инерции и хаоса трагического Времени, проблема сохранения академических традиций отражают жизненные ценности, принципы, философские взгляды и эстетические идеалы композитора. «Мир сошел не с ума, а с сердца!», - пишет Николай Карлович Метнер в письме к своему брату Эмилию Карловичу Метнеру, известному литератору, публицисту своего времени, который был близок кругу поэтовсимволистов и русских религиозных философов [2. С. 257].

Вынужденная эмиграция в 1921 г., смена привычного уклада жизни и потеря своего «духовного отечества» нашли воплощение в философском мировоззрении Н.К. Метнера и повлияли на содержание его творчества. Четырна- 
дцать фортепианных сонат композитора являются ярким выражением противоречий диалога художника и современной ему эпохи. Сонаты Н.К. Метнера, как отмечают исследователи, синтезируют классические, романтические, западноевропейские и русские традиции, представляют неоклассическое направление. «У почитаемых им предшественников - Баха, Бетховена, Шуберта, Брамса - Метнер почерпнул и индивидуализировал необходимые ему качества музыкального искусства: глубину мысли, мужественную динамику, драматизм, предельную ясность, выстроенность формы» [3. С. 141].

«Трагическая соната» op. 39 c-moll Н.К. Метнера, созданная в 20-х гг. $\mathrm{XX}$ в., когда композитор находился в эмиграции, входит в состав второго цикла пьес «Забытые мотивы» и является одной из наиболее известных и часто исполняемых сонат. Первое исполнение этого сочинения состоялось в авторском концерте в Америке (1928). Трагическое, философское мировосприятие композитора, ностальгические размышления о судьбе России, возрождение символических образов безвозвратно ушедшего мира, безусловно, оказали влияние на концепцию сонаты.

Специфику содержания «Трагической сонаты» целесообразно рассмотреть на основе привлечения методов целостного и семантического анализа музыкального текста, позволяющих выявить взаимосвязь между мышлением художника и семантическим пространством культуры. Основополагающими для семантического анализа «Трагической сонаты» являются понятия «экстрамузыкальной» и «интрамузыкальной» семантики, «структурно-семантического инварианта жанра», изложенные М.Г. Арановским в работах «Музыкальный текст: структура и свойства», «Симфонические искания» [4, 5]. Важно отметить, что под «интрамузыкальной семантикой» ученый понимает значения, полученные в процессе семантического анализа текста, в результате взаимодействия системы музыкального языка и внутритекстового контекста. Подчеркивая взаимосвязь интрамузыкального и экстрамузыкального семантического содержания текста, М.Г. Арановский отмечает, что под экстрамузыкальной семантикой «подразумевается, собственно, область коннотаций, которая возникает в результате выхода за пределы чисто интрамузыкальной семантики» [4. С. 318], которыми могут быть слово, чувство, мысль, идея и другие «внемузыкальные» и «экстрамузыкальные стимулы», определяющие содержание произведения [6. С. 120]. Духовный опыт, идея композитора, которые, «прежде всего, относятся к внемузыкальным причинам творчества» [Там же. С. 128], будут рассмотрены как «экстрамузыкальная область» (по М. Г. Арановскому), влияющая на концепцию сонаты.

По замыслу художника «Трагическая соната» op. 39 c-moll должна звучать вместе с «Утренней песней» («Canzona matinata» op. 39 G-dur) как единый образно-драматургический цикл. По воспоминаниям пианистки Эдны Айлз, известна авторская рекомендация Н.К. Метнера: «Трагическая соната должна всегда исполняться вместе с Утренней песней. Это объясняется тем, что оба произведения имеют одну и ту же тему и Соната должна исполняться после Утренней песни attacca» [7. С. 158]. Именно так исполнял эти сочинения на своих концертах Н.К. Метнер. В истории развития жанра сонаты, как отмечает Д.В. Житомирский, сочинения Н.К. Метнера представляют неоклассическую модель, в которой представлено «слияние идеалов «романти- 
ческого» и «классического» искусства [8. С. 292]. Уникальность данного цикла заключается в том, что содержание «Утренней песни», лирического центра композиции, отражает, по сути, философскую концепцию «Человека мыслящего», а «Трагическая соната» реализует концепцию «Человека действующего» [5. С. 24]. Это и определило особенности «структурносемантического инварианта жанра» [Там же. С. 25], экзистенциальное содержание настоящей сонаты. Таким образом, семантика композиции «Утренней песни» (1-я часть) и «Трагической сонаты» (2-я часть), может быть рассмотрена как двухчастный цикл с чертами классицизма и романтизма.

Особенности драматургии и семантического содержания «Трагической сонаты» важно представить в опоре на понятия музыкально-художественного и концептуального времени, в которых отразились философское мировосприятие и художественно-эстетические взгляды композитора. В зависимости от понимания феномена Времени и подходов к его изучению в современной литературе выделяются: историческое время, реальное время, философское время, перцептуальное время, художественное время и др. [9]. Природа музыкально-художественного времени в данной статье будет рассматриваться на основе изучения особенностей семантического содержания образовсимволов трагического Времени и Вечности, выражающих философскую концепцию сонаты и определяющих специфику ее жанрового инварианта.

Экстрамузыкальное семантическое содержание «Трагической сонаты» выражено в программном названии и диалоге образов-символов сонаты c-moll c музыкальными символами других эпох (на уровне контекста и интертекста). Тема «трагического» неоднократно, как лейтмотив, подчеркивалась Н.К. Метнером в сочинениях, таких как «Трагические отрывки» (op. 7 a-moll, g-moll), «Траурный марш» (op. 31 h-moll), а также неопубликованное «Траурное адажио» (e-moll). Значительную роль в формировании драматического содержания сонаты играет и семантика тональности, которая в процессе восприятия текста формирует многослойное пространство смыслов. Тональность c-moll, в которой написана «Трагическая соната», отличается устойчивым трагедийным семантическим значением. Насыщенный героический драматизм сонаты в семантическом плане близок патетическим образам до-минорных сонат Л. Бетховена («Патетическая соната» № 8 op. 13 c-moll) и Ф. Шопена (Соната № 1 op. 4 c-moll).

Интрамузыкальное семантическое содержание «Утренней песни» и «Трагической сонаты» представлено лирической и драматической образными сферами, отразившими противопоставление символических образов Времени как трагического настоящего и образов Вечности как воспоминания об идеалах прошлого. Музыкально-художественное время и понятие «символический образ» многосторонне рассматриваются в трудах С.С. Аверинцева [10], М.М. Бахтина [9] и др. По мысли С.С. Аверинцева, «...символ есть образ, взятый в аспекте своей знаковости», «он есть знак, наделенный всей органичностью мифа и неисчерпаемой многозначностью образа. Всякий символ есть образ» [10. С. 155]. Важно отметить, что в концепции сонаты воплотились экзистенциальные символические образы трагического Времени и лирикофилософские, лирико-эпические образы Воспоминаний. 
Трагедийная сфера образа-символа Времени представлена в «Трагической сонате» комплексом тем: Воли, Судьбы, Грозовой волны, Колокольного звона - комплексом, формирующим стабильное структурно-тематическое пространство и выражающим основную направленность экстрамузыкального и интрамузыкального семантического содержания сонаты.

Важным образно-драматургическим и семантическим значением в сонате обладает тема-символ Воли, впервые появляющаяся во вступлении сонаты (т. 1-2). В первых тактах компактной темы-тезиса сосредоточены мужество и внутренняя энергия, которые подчеркиваются октавным изложением и мощными аккордами. Особым средством выразительности являются паузы, которые помогают передать суровый, драматический образ, декламационный способ высказывания темы. В процессе драматургического развития темасимвол Воли претерпевает значительную образно-смысловую трансформацию. Так, в экспозиции после второго проведения главной партии эта тема звучит более сдержанно (т. 58), в заключительном разделе экспозиции становится вновь напористой и динамичной (тт. $96,101,105)$. В фугато (т. 152) разработки тема-символ Воли звучит декламационно, перед репризой разворачивается в расширенном диапазоне, усиливающем драматический потенциал образа. Посредством динамического развития темы-символа Воли в сонате представлен феномен трагического Времени.

Особенности семантического содержания «Трагической сонаты» могут быть также рассмотрены на основе понятия «мигрирующая интонационная формула». Так, Л.Н. Шаймухаметова отмечает: «...мигрирующие интонационные формулы - это устойчивые обороты с закрепленными значениями, способные вызывать конкретные предметно-образные представления. Интонации с закрепленными значениями активно мигрируют в тематизме различных текстов, обогащая музыкальный язык и конкретизируя содержание произведения» [11. С. 19]. Тема-символ Воли, по сути, является «мигрирующей интонационной формулой», поскольку играет значительную роль в драматургии других сонат Н.К. Метнера, таких как Соната оp. 5 f-moll (т. 20, главная партия), Соната оp. 25 e-moll (тт. 76-79, связующая партия экспозиции первой части, т. 147 в разработке), а также «Грозовая соната» оp. $53 \mathrm{f}$-moll (т. 57, побочная партия). Рассматривая особенности семантического проявления темы-символа Воли и ее формирования на разных уровнях текста и контекста, а также ее интертекстуальных и внутритекстовых значений, важно подчеркнуть драматургическую роль, которую она выполняет для воплощения трагической символической сферы в сонате.

Символическое содержание первой главной партии можно рассмотреть как особое Время героя, его восприятие, эмоциональные переживания драматических событий и образов. Семантика движения в первой главной партии выражена через тему-символ Грозовой волны, которая проявляется в арпеджированной фактуре, стремительном бурном потоке пассажей в левой руке (тт. 4-9). В разработке происходит дальнейшее развитие, динамизация образа-символа Грозовой волны (т. 114), представленного активным ладогармоническим движением, подчеркивающим неустойчивый, тревожный характер темы. Отметим, что семантика темы Грозовой волны носит сугубо контекстуальный характер. 
В процессе драматургического развития «Трагической сонаты» возрастает «градус» напряжения, происходит динамизация основных тем, символизирующих образ трагического Времени. На кульминации разработки и всей сонаты после фугато впервые появляется тема-символ Судьбы (т. 198). Символическое, интрамузыкальное и экстрамузыкальное семантическое содержание этой темы выражено характерным выразительным и узнаваемым ритмическим рисунком, впервые введенным Л. Бетховеном в Пятой симфонии. Масштабность звучания темы-символа Судьбы подчеркивается широким диапазоном фактуры, семантикой триольного ритма, активным динамическим развитием темы, которые усиливают драматический контур образа, рисуют духовное смятение главного героя.

Тема-символ Судьбы знаменует необратимость драматических событий сонаты и подкрепляется появлением темы-символа Колокольного звона (т. 192), символическое содержание которого обладает двойственной функцией. С одной стороны, эта тема символизирует образ трагического настоящего Времени («набат») как предвестник надвигающихся драматических событий, с другой - принадлежит образу Вечности (колокола как сакральный, духовный символ Веры). Семантика темы-символа Колокольного звона проявляется в мощном аккордовом изложении, полиритмии, октавном удвоении фактуры, имитирующей удары набата в драматической кульминации «Трагической сонаты».

Важно отметить, что семантическое пространство основных тем трагического Времени формируется в сонате благодаря сложным, многообразным связям и взаимодействию разных смысловых «семантических полей», контекстов. М.Г. Арановский подчеркивает, что тема главной партии Пятой симфонии Л. Бетховена, представляющая собой «гигантский символ» Судьбы, вырастает из «четырехзвучной структуры», «в контексте всей симфонии, вбирая в себя все присущие ей смысловые связи» [6. С. 119]. То же можно сказать и о семантическом содержании основных тем-символов Трагической сонаты - Воли, Судьбы, Грозовой волны, Колокольного звона: только в контексте целого, в процессе динамического развития Трагической сонаты они обретают глубинный, символический смысл.

Символическим образам трагедийного настоящего Времени противостоят лирические темы, связанные с ностальгическими воспоминаниями о прошлом как символе вечно прекрасных духовных ценностей. Феномен Вечности принято рассматривать как одно из проявлений бесконечного времени, как выражение сакрального мира, духовного бытия. В данном контексте с понятием Вечности также связаны мысли, идеи Н.К. Метнера о служении идеалам и ценностям классического искусства ${ }^{1}$. По мнению Е.Б. Долинской, лирические образы являются центром музыкального мира Н.К. Метнера, выразившим суть его личности и авторского подчерка: «Подлинной стихией композитора оказалась лирика. В лучших его работах пленяют образы человека с мечтательной и возвышенной душой, образы вдохновенной юношеской любви, упоение радостями жизни и красотой природы» [12. С. 163].

\footnotetext{
${ }^{1}$ Возвышенное отношение к лирике объединяет Н.К. Метнера и С.В. Рахманинова, в содержании лирических образов композиторам удается воплотить внутреннее глубинное переживание человека, представить мировосприятие Времени художника-творца.
} 
Рассматривая интрамузыкальное семантическое содержание лирикофилософской сферы в «Трагической сонате» Н.К. Метнера, отметим его контрастное сопоставление с драматическими образами первой главной партии сонатного аллегро. Символические образы Вечности представлены лирикоэпическими темами «Утренней песни» и лирико-психологической темой Воспоминаний, обладающей рефлексивной, экзистенциальной углубленностью, ностальгической тоской по прошлому, уходящему времени. Впервые в творчестве Н.К. Метнера тема-символ Воспоминаний появляется во вступлении к Сонате op. 38 a-moll, представленной в первом цикле пьес «Забытые мотивы». В этой связи отметим, что тема Воспоминаний, как и тема Воли и тема Судьбы, может быть рассмотрена как «мигрирующая интонационная формула», которая расширяет семантический контекст восприятия символических образов «Трагической сонаты» и «Утренней песни».

В художественно-эстетических взглядах Н.К. Метнера, посвященных идее сохранения классических устоев современного ему искусства, песня является одним из символов, направленных на сохранение глубинных основ «корневой» системы музыкального «древа». Композитор пишет: «Когда-то прозвучавшая в мире первая песня оставила в душе человеческой единый “живой звук”, и звук этой песни стал исходной точкой для согласования между собой всех других звуков» [13. С. 24]. Эти размышления композитора определяют характер развития концептуального и музыкально-художественного времени в сонате. Лирические образы «Утренней песни» представляют авторское время, которое выражает идею служения классическому искусству и олицетворяет образ-символ Вечности. Образ-символ трагического Времени представлен в концепции сонаты и отражен в переживаниях исторических событий эпохи и драматическом времени лирического героя.

Тема Воспоминаний, благодаря красоте песенной мелодии, является символом единства духовности и простоты, характерным для музыкального мышления Н.К. Метнера. Семантика колыбельной через покачивающийся, монотонный ритмический рисунок аккомпанемента определяет характер темы Воспоминаний. Как пишет О. Кривонос, исследователь творчества Н.К. Метнера, «идея воспоминания как воспроизведения, воссоздания некого скрытого, существующего подсознательно пласта «знания», воплощенного в музыкальные образы, формировала и сам творческий процесс композитора» [14. C. 81].

Образ-символ Воспоминаний является важным семантическим звеном, объединяющим композицию «Утренней песни» и «Трагической сонаты». Отметим, что побочная партия «Трагической сонаты» построена на теме Воспоминаний, впервые прозвучавшей в среднем разделе «Утренней песни» и образующей смысловую арку к сонате. В процессе драматургического развития показательна семантика тонального содержания темы Воспоминаний, свидетельствующая о ее смысловом преобразовании из лирико-философской, медитативной, в лирико-драматическую, тревожную и взволнованную. Так, впервые тема Воспоминаний звучит в «Утренней песне» (fis-moll), в побочной партии (g-moll) и разработке сонаты, в тональности скорби h-moll, имеющей устойчивое семантическое значение ${ }^{1}$.

\footnotetext{
${ }^{1}$ Бах И.С. Mecca h-moll; Лист Ф. Соната h-moll.
} 
В разработке сонаты образ-символ Воспоминаний выражен в противопоставлении двух семантических элементов - мотива скорби (cantando) и мотива протеста (rinforzando) (тт. 188-191). Раздвоенность, внутренняя борьба конфликтных образных сфер приводят в кульминации разработки (тт. 192203) к утверждению трагической сферы. Отсутствие побочной партии (темы Воспоминаний) в репризе говорит о композиционном, смысловом эллипсисе и драматическом итоге сонаты - крушение надежд лирического героя, обреченность его попыток противостоять суровому внешнему миру, что в целом выражает трагедийное мироощущение художника. Такое развитие темы Воспоминаний показывает, как происходят ее динамизация и расширение смыслового диапазона в пределах цикла, и, благодаря преобразованию внутритекстового контекста, происходит «уточнение семантического смысла» [6. С. 118], глубинного содержания этой темы, т.е. становление образа-символа Вечности.

Диалогическое взаимодействие образов-символов Времени и Вечности в сонате, определяющее характер музыкального мышления, может быть представлено и через сопоставление особенностей развития континуального и дискретного времени. «Музыка, как и всякое искусство вообще, акцентирует континуальную составляющую мышления. Однако и в музыке мы легко обнаруживаем некую модель логически формулируемого, дискретного мышления: это традиционные классические темы-мелодии, замкнутые в своем строении...» [15. С. 32]. Динамичное, процессуальное развитие символических образов трагической сферы в драматургии сонаты представлено континуальным временем и выражено темами Воли, Судьбы, Грозовой волны, Колокольного звона с своеобразным несимметричным, разработочным характером изложения музыкального материала. Напротив, для воплощения символа Вечности, представленного в лирических образах «Утренней песни», теме Воспоминаний, характерно логически оформленное симметричное время, составляющее основу дискретного музыкального мышления.

В целом на примере «Трагической сонаты» были рассмотрены сложные структурно-семантические процессы и специфика жанрового инварианта сонаты в контексте особенностей фортепианного творчества Н.К. Метнера. Основное содержание «Трагической сонаты», философское мировосприятие времени были рассмотрены с помощью понятий экстрамузыкальной и интрамузыкальной семантики, действующих на микро- и макроуровнях музыкально-художественного становления. В процессе анализа музыкально-художественного времени на уровне развития тематизма было отмечено действие «мигрирующих интонационных формул», определяющих стабильные компоненты музыкального изложения (тема Воспоминания, тема Судьбы), а также мобильные (темы, определяющие сферу Трагического времени) компоненты музыкального мышления. Благодаря анализу историко-культурного контекста и философско-эстетических взглядов Н.К. Метнера раскрываются особенности неоклассического стиля композитора, содержание экстрамузыкальной семантики, выраженное в диалогическом сопряжении образов-символов Времени и Вечности. Рассмотрена логико-семантическая концепция сонаты, существующая в двух временных измерениях - времени автора (ностальгическое, идеальное прошлое) и времени лирического героя (трагическое настоящее). 
В семантическом содержании музыкального текста и контекста образсимвол Вечности выражается лирическими образами «Утренней песни» и темой Воспоминаний в «Трагической сонате», олицетворяет стремление художника сохранить истинные, духовные ценности культуры прошлого. Семантика образа-символа трагического Времени представлена разносмысловыми контрастными драматическими символическими темами - Воли, Судьбы, Грозовой волны, Колокольного звона и выражает картину мировосприятия и переживания лирического героя. В целом трактовка «концептуального времени» в «Трагической сонате» определяется художественноэстетическими взглядами Н.К. Метнера, связанными с «генерированием замысла произведения» на основе синтеза лирико-эпического и лирикодраматического способов высказывания, что характерно для музыкального мышления композитора [16. С. 4038].

Осмысливая концепцию и драматургию сонаты, удалось рассмотреть особенности «структурно-семантического инварианта жанра» как образец поэмно-романтического типа: «Утренняя песнь» - лирико-философское вступление, «Трагическая соната» - лирико-драматическое сонатное allegro. Драматическая концепция сонаты, семантическое содержание основных символических образов цикла выражают философскую, экзистенциальную идею Н.К. Метнера, направленную на сохранение вечных ценностей: «Искусство само по себе есть одно из высочайших чувств, идей и переживаний всего человечества...» [13. С. 113]. Таким образом, в «структурно-семантическом инварианте» сонаты выражен диалог образов-символов Времени и Вечности, который отражает философские размышления Н.К. Метнера о музыкальном искусстве и трагических событиях рубежа XIX-XX вв.

\section{Литература}

1. Толстой Л.Н. Полн. собр. соч. : в 90 т. М.,1936. Т. 36.742 с.

2. Метнер Н.К. Письма / сост. З.А. Апетян. М.: Сов. композитор, 1973. 615 с.

3. Келдыш Ю.В. Н.К. Метнер // История русской музыки, 1890-1917 гг. М., 1997. Т. 10 А. C. $134-169$.

4. Арановский М.Г. Музыкальный текст : структура и свойства. М.: Композитор, 1998. 343 с.

5. Арановский М.Г. Симфонические искания: исследовательские очерки. Л.: Сов. композитор, 1979. $287 \mathrm{c}$.

6. Арановский М.Г. Мышление, язык, семантика // Проблемы музыкального мышления. М., 1974. С. 90-128.

7. Рахленко И.О. Николай Метнер и Эдна Айлз. Творческие контакты // Николай Метнер. Вопросы биографии и творчества. М., 2009. С. 145-169.

8. Житомирский Д.В. Н.К. Метнер (заметки о стиле) // Житомирский Д.В. Избранные статьи. М.: Советский композитор, 1981. С. 283-329.

9. Бахтин М.М. Эстетика словесного творчества. М.: Искусство, 1979. 423 с. 161.

10. Авериниев С.С. София-Логос. Словарь. 2 изд., испр. Киев: Дух і Літера, 2001. С. $155-$

11. Шаймухаметова Л.Н. Мигрирующая интонационная формула как феномен музыкального мышления // Проблемы музыкальной науки. 2011. № 2. С. 18-25.

12. Долинская Е.Б. Николай Метнер. М.: Музыка, 1966. 192 с.

13. Метнер Н.К. Муза и мода. Защита основ музыкального искусства. Париж: YMCA PRESS, 1978. $156 \mathrm{c}$.

14. Кривонос O. Феномен воспоминания и его интерпретация в «Сонате-Reminiscenze» Н.К. Метнера // Киівське музикознавство. Вип. 2: Проблеми музичноі інтерпретаціі: зб. статей. Киев, 1999. С. 79. 
15. Валькова В.Б. Музыкальный тематизм - мышление - культура. Н. Новгород: Изд-во ННГУ, 1992. $161 \mathrm{c}$.

16. Шитикова Р.Г. Синтез лирики, драмы и эпоса в сонатах Н.К. Метнера // Фундаментальные исследования. 2015. № 2-18. С. 4038-4043.

Predvechnova Ekaterina O. Glinka Novosibirsk State Conservatoire (Novosibirsk, Russian Federation)

E-mail: garmonija_nsk@mail.ru

Tomsk State University Journal of Cultural Studies and Art History, 2017, № 26, pp. 101-110.

DOI: $10.17223 / 22220836 / 26 / 11$

THE SEMANTICS OF THE IMAGE-SYMBOL TIME IN «TRAGIC SONATA» OP. 39 CMOLL BY N.K. MEDTNER

Key words: N.K. Medtner; piano works; «Tragic Sonata»; «Morning Song»; semantic analysis; the semantics of images and symbols of Time.

In the modern musicology particular importance are studies the traditions of Russian piano art. In this context, it is necessary to turn to the piano works by Nikolai Medtner, which express the philosophical and aesthetic world of the composer, aimed at protecting the spiritual foundations of music. "Tragic Sonata" (Op. 39-moll) reflects the worldview of the artist, his experience of the tragic events of the era, embodies the ideals and values of Russian culture of the Silver Age.

The aim of the study is to analyze the images of time and eternity in the aspect of semantics "Tragic Sonata" and "Morning Song", belonging to the same cycle of works "Forgotten Motives" Op. 39. In the article the following tasks are: to consider the aesthetic and philosophical views of the composer, embodied in the content of symbolic images of Time and Eternity; explore the features and ekstramusical and intramusical semantics in the thinking of the composer; introduce "structural and semantic genre invariant" in "Tragic Sonata".

The study of the "Tragic Sonata" by N.K. Medtner based on holistic techniques and semantic analysis. The methodological basis at the semantic analysis of the sonata were works by M.G. Aranovsky, L.A. Kupriyanova, L.N. Shaimukhametova. Studies by E.V. Vasyutinskaya, E.B. Dolinskaya, K.V. Zenkin, I.Z. Zetel, U. V. Keldysh, O.V. Sokolov, dedicated to the piano works of Nikolai Medtner, helped to analyze the features musical thinking of composer. The material for the study is based on "Morning Song" or.39 G-dur and "Tragic Sonata" or.39 c-moll by N. K. Medtner.

The novelty of the work is to understand the deep meaning of the philosophical concept of the sonata c-moll, realized in the dialogue of images Time and Eternity, manifested in dramaturgy and "structural and semantic invariant". For the first time in the analysis of "Tragic Sonata" applied methods ekstramusical and intramusical semantics (M.G. Aronofsky).

As a result, disclosed features of the "structural and semantic genre invariant" Sonata of poemromantic type, where the "Morning Song" is considered as the first part of the lyrical and philosophical, and "Tragic Sonata" is a dramatic ending cycle. In the first part of a two-part composition ( "Morning Song") is represented by the author of Time through the song images symbols of Eternity, the theme of Remembrance. In the second part of the composition - "Tragic Sonata" - presented the lyrical time, expressed in the theme of Destiny. Thus, the semantic content of the main symbolic spheres of Time and Eternity reflect the composer's musical thinking.

\section{References}

1. Tolstoj L. N. Poln. sobr. soch.: v 90 t. [Complete works] M.,1936. T. 36. 742 s.

2. Metner N. K. Pis'ma [Letters] / Sost. Z. A. Apetjan. M.: Sov. kompozitor, 1973. 615 s.

3. Keldysh Ju. V. N. K. Metner [N. K. Medtner ] // Istorija russkoj muzyki, 1890-1917 gg. M., 1997. T. 10A. S. 134-169.

4. Aranovskij M. G. Muzykal'nyj tekst: struktura $i$ svojstva. [Musical text: structure and properties]. M., «Kompozitor», 1998. $343 \mathrm{~s}$.

5. Aranovskij M.G. Simfonicheskie iskanija: issledovatel'skie ocherki. [Symphonic Hunt: research essays]. L.: Sovet. kompozitor, 1979. 287 s.

6. Aranovskij M. G. Myshlenie, jazyk, semantika [Thinking, language, semantics] // Problemy muzykal'nogo myshlenija [Problems of musical science]. M., 1974. S. 90-128. 
7. Rahlenko I. O. Nikolaj Metner i Jedna Ajlz. Tvorcheskie kontakty [Nikolai Medtner and Edna Iles: creative contacts] // Nikolaj Metner. Voprosy biografii i tvorchestva [Nikolai Medtner: questions of the biography and creativity]. M., 2009. S. 145-169.

8. Zhitomirskij D. V. N. K. Metner (zametki o stile) [Nikolai Medtner: notes about style] // Zhitomirskij D. V. Izbrannye stat'i [Featured article]. M.: Sovetskij kompozitor, 1981. S. 283-329.

9. Bahtin M. M. Jestetika slovesnogo tvorchestva. [Aesthetics of verbal creativity]. M.: Iskusstvo, 1979. $423 \mathrm{~s}$.

10. Averincev S.S. Sofija-Logos. Slovar' [Sofiya-Logos. Dictionary]. 2-e, ispr. izd. K.: Duh i Litera, 2001. S. 155-161.

11. Shajmuhametova L. N. Migrirujushhaja intonacionnaja formula kak fenomen muzykal'nogo myshlenija [Migrans intonation formula as phenomenon of musical thinking] // Problemy muzykal'noj nauki [Problems of musical science], №2. Ufa, 2011. S.18-25.

12. Dolinskaja E. B. Nikolaj Metner [Nikolai Medtner ]. M.: Muzyka, 1966. $192 \mathrm{s.}$

13. Metner N. K. Muza i moda. Zashhita osnov muzykal'nogo iskusstva. [Muse and Fashion: protection of the foundations of musical art]. Parizh: YMCA PRESS, 1978. $156 \mathrm{~s}$.

14. Krivonos O. Fenomen vospominanija $i$ ego interpretacija $v$ «Sonate-Reminiscenze» N.K. Metnera [The phenomenon of memories and its interpretation in «Sonata-Reminiscenze» by N.K. Metner] // Kiivs'ke muzikoznavstvo. Vip.2. Problemi muzichnoi interpretacii. Zb. Statej [Problems of musical interpretation. Digest of articles]. K.,1999. S.79

15. Val'kova V.B. Muzykal'nyj tematizm - myshlenie - kul'tura [Musical thematism-thinkingculture]. N. Novgorod: Izd-vo NNGU, 1992. $161 \mathrm{~s}$.

16. Shitikova R.G. Sintez liriki, dramy i jeposa v sonatah N.K. Metnera [Synthesis of poetry, drama and epic in the sonatas of Medtner] // Fundamental'nye issledovanija [Fundamental research]. 2015. № 2-18. S. 4038-4043. 